\title{
Notes on the International Genome Project Meeting
}

\section{By Mike Moralis}

$\mathrm{H}$ UNDREDS OF THE LEADING GENOMIC researchers from around the globe descended on Vancouver in April for HGM2000, the International Human Genome Meeting, to discuss the essence of biology and what it means to be human in an atmosphere of excitement and expectation.

"Such a mood must have permeated physics research at the beginning of the 20th Century," observed honourary conference chair Dr. Michael Smith of the University of British Columbia, who earned a Nobel Prize in 1993 for his work on site-directed mutagenesis, a technique used to understand the function of genes and proteins in medical and biological research. "This very same mood permeates biological research at the beginning of the 21 st Century."

The field of genomics, rooted in fundamental genetics, was named a little more than a decade ago. The Human Genome Project is an international collaboration aimed at mapping the entire human genetic blueprint, officially launched in 1989. The process involves deconstructing the entire double helix structure of DNA contained in every single gene.

It is like learning English as a foreign language in order to appreciate literature. The first step is to learn the alphabet; then you have to learn grammar and vocabulary. Somewhere along the way, the elegance of Shakespeare becomes evident.

Genomic research is tantalizing, because researchers are simultaneously learning the genetic alphabet, and decoding portions or sequences of the genetic structure. The genetic alphabet of the human genome consists of cells, each containing 23 chromosomes made up of twin strands of DNA molecules, arranged in a helix structure. Genes are segments of DNA which contain coded instructions that control cells. This affects the way cells are organized, and the proteins they produce.

This process of mapping the human genome in a coordinated manner has been underway for a little more than a decade. Milestones are reported periodically in journals and the media, focused on new insights into a specific disease or condition.

The human DNA sequence contains about three billion pairs of one of four chemicals: adenosine, cytosine, thymine and guanine, or A, C, T and G. The DNA map reached its two-billionth unit, $T$, earlier this year when data from England was deposited in the international database. The theme of the first plenary session of the conference was "the beginning of the end," recognizing that the human genome will be fully mapped within a couple of years.

Genome mapping and sequencing has proceeded on an exponential basis, largely through the introduction of information technology. Once the sequence is more or less decoded, patterns of genetic variation can be compared and linked to disease incidence and susceptibility.
"We are poised for tremendous positive changes in health and science," incoming President of the Human Genome Project Dr. Lap-Chee Tsui said, noting that a "first draft" of the human genome should be completed this year.

The implications at the macro level are that genomic research, and its younger sister field, proteomics, will transform diagnosis and treatment of many diseases. The promise of gene therapy to cure diseases is taking shape. Disease prevention will enter a new era, as people with genetic susceptibility to a given disease will be able to take precautionary measures long before diagnosis is an issue. Cloning human beings is already technically feasible.

Some of these issues embody the classic ethical dilemma of science: just because something can be done doesn't mean it should be done, but at the same time it is almost inevitable that someone will do it.

Dr. Francis Collins, director of the Human Genome Project in the United States, warned that the ability to screen for genetic diseases creates a risk of genetic discrimination by employers and insurers.

Another undercurrent at the conference was the ongoing tension between Human Genome Organization researchers and PE Celera Corp. of Maryland, founded less than two years ago by Dr. Craig Venter. While public- and privatesector researchers are collaborating increasingly, Celera was created to beat the Human Genome project in the mapping race, and capture potentially valuable patents along the way. The general consensus is that the basic genetic information being generated should be part of the public domain, while patents should be reserved for data that has some specific utility. Dr. Gert-Jan Van Ommen of Leiden University in the Netherlands, chair of the Human Genome Organization's intellectual property rights committee, said about 20,000 patent applications have been filed for basic DNA data, most of which should not be granted.

Another ethical concern aired at the conference is the question of compensation for donors of genetic material used by researchers. University of Montreal law professor Dr. Martha Knoppers, chair of the Human Genome Organization's international ethics committee, suggested that there should be some form of compensation, but not direct financial payment, for donors. Knoppers called on biotechnology companies to commit a portion of their profits - up to three per cent - to public health care and international assistance. There was also some discussion of the government of Iceland, which has struck a deal to sell a wide range of genetic and other data regarding its 270,000 residents to a private company.

As the head of the former Medical Research Council Dr. Henry Friesen observed: "Science, like politics, cannot move too far ahead of public opinion. If it does, we risk creating an environment of public fear and unrest." 